\title{
Referenzwertermittlung von Schilddrüsenparametern im Serum für den Raum Berlin (West) unter besonderer Berücksichtigung jvon Alters- und Geschlechtsabhängigkeit
}

L. Röcker, Ch. Janiszewski, W. Hopfenmüller

technische Assistenz: B. Heyduck

Zusammenfassung:

Ziel der vorliegenden Arbeit war es, neue Referenzwertbereiche für die wichtigsten Schilddrüsen-in-vitroParameter für den Raum Berlin(West) zu erstellen. Hierfür wurde nach klinischen und laborchemischen Kriterien ein ausreichend großes und somit für den Raum Berlin (West) repräsentatives Euthyreosekollektiv ausgewählt. Das Kollektiv besteht aus 179 Probanden; 101 Frauen und 78 Männer.

Die wichtigsten Störfaktoren (insbesondere extrathyreoidale Erkrankungen und Medikamente), welche die Schilddrüsendiagnostik beeïnflussen können, fanden als Ausschlußkriterien für das erstellte Euthyreosekollektiv ihre Berücksichtigung. Für den erfaßten Altersbereich vom 20. - 64. Lebensjahr konnten bis auf einen signifikant erniedrigten T3-Wert in der Altersklasse vom 50. - 64. Lebensjahr im Männerkollektiv keine weiteren Altersabhängigkeiten aufgezeigt werden.

Bezüglich der Geschlechtsunterschiede lagen der fT3- und fT4-RIA im Frauenkollektiv signifikant niedriger als im Männerkollektiv.

Die Gesamthormonkonzentrationen (T3, T4), die Transportproteine und das basale TSH zeigen keine Geschlechtsabhängigkeiten.

Um den Östrogeneinfluß darzustellen, wurden die Kollektive Frauen mit hormoneller und Frauen ohne hormoneller Kontrazeption miteinander verglichen. Wir sahen unter Östrogeneinfluß einen hochsignifikanten Anstieg der Proteinbindungskapazität, der Gesamthormone (T3, T4) und des rT3 bei Erniedrigung der T4:TBG-, T3:TBG-Quotienten. Bezüglich der fT3- und fT3-RIAs zeigten sich konstante östrogenunabhängige Werte.

Ein entscheidendes Ergebnis dieser Untersuchungen ist der Nachweis, daß die Mehrzahl der SchilddrüsenParameter keine normal verteilten biologischen Größen sind. Aufgrund dieser Feststellung wurde bei der Erstellung der Referenzbereiche die Perzentilenmethode angewandt.

Die statistischen Ergebnisse des Gesamtkollektivs und der verschiedenen Subkollektive sind tabellarisch dargestellt.

\section{Schlüsselwörter:}

Referenzwerte - Schilddrüsenhormone

\section{Summary:}

The aim of the present study is to establish new ranges for reference values of the most important thyroid in-vitro parameters for the area of Berlin (West). For that reason, according to clinical and laboratory chemical criteria, we have selected an adequately large and therefore for the area of Berlin (West) representative euthyroidal collective. The test group consists of 179 subjects, 101 women and 78 men.

The main disturbing factors (especially extrathyroidal diseases and medications), which may influence the thyroid gland, were taken into consideration as criteria to exclude subjects from the established group.

For the age range of this study (20 to 64 years), no more age-dependent changes were noticed, with the exception of the significant decrease of T3 in the 50 to 64 year-old subjects in the male group.

With regard to the variations between the sexes, fT3-and fT4-RIA values were significantly lower in the female group than in the male. The total hormone concentration (T3, T4), transport proteins and the basal TSH show no sex dependencies. In order to present the oestrogene influence we compared two groups of women, one having taken hormonal contraception and the other not. Under the influence of oestrogene we found a highly significant increase in the protein binding capacity, the total hormones (T3, T4) and the rT3 with a reduction in T4:TBG-, T3:TBG-ratios. With respect to fT3-and fT4-RIAs we found constant oestrogene-independent values. $A$ decisive result of these investigations is that the majority of the thyroid gland parameters are not normally distributed.

Based on this fact, the percentile method was applied to establish the reference ranges.

The statistical results of the total collective and the various sub-collectives are shown in the tables.

Keywords:

Reference values - thyroid hormones 


\section{Einleitung}

Zur Diagnostik der Schilddrüsenerkrankungen stehen neben den klinischen Befunden eine Vielzahl von in-vitround in-vivo-Parametern zur Verfügung. Besonders durch die in den letzten Jahren zahlreich entwickelten Methoden der radioimmunologischen (RIA) und immunradiometrischen (IRMA) Bestimmungen der Schilddrüsenhormone im Serum können auch Routinelaboratorien Ergebnisse von hoher Aussagekraft erzielen.

Bei der Erstellung von Referenzbereichen zur Beurteilung von Schilddrüsenhormonwerten muß allerdings beachtet werden, daß die Konzentrationen der Schilddrüsenhormone von einer Vielzahl von Einflußgrößen abhängen. So müssen biologische Faktoren wie z. B. Alter und $\mathrm{Ge}$ schlecht berücksichtigt werden. Von besonderer Bedeutung ist ferner die genaue Erfassung von Nebenerkrankungen und deren Medikationen. Abgesehen von diesen präanalytischen Faktoren schwanken die Schilddrüsenhormonwerte im Serum ganz erheblich in Abhängigkeit von der analytischen Methode. Auch regionalen Unterschieden muß Rechnung getragen werden. Es wird daher gefordert, daß jede Untersuchungsstelle eigene Referenzwerte für die von ihr angewandten Methoden und für ihr Einzugsgebiet an einer ausreichend großen Zahl von schilddrüsengesunden Probanden ermittelt.

Bei sehr vielen Publikationen wurde ein ausreichend großes, repräsentatives Kollektiv nur auf retrospektivem Wege erstellt oder aus dem Pool von stationär oder ambulant behandelten Patienten einer Klinik ausgewählt. Es handelte sich also in den meisten Fällen um Patienten mit verschiedenen Vor- bzw. Nebenerkrankungen (15).

In der vorliegenden Arbeit wurden an einem größeren Kollektiv schilddrüsengesunder Probanden neue Referenzwertbereiche für die wichtigsten Schilddrüsen-in-vitro-Parameter für den Raum Berlin (West) erstellt. Hierbei wurden verschiedene analytische Methoden verwandt unter sorgfältiger Berücksichtigung der momentan bekannten Einflußgrößen.

\section{Material und Methodik}

\section{Experimentelle Durchführung der Untersuchung}

\subsection{Charakterisierung und Auswahlkriterien der Untersuchungsteilnehmer}

In der vorliegenden Untersuchung wurde auf prospektivem Wege ein Probandenkollektiv erstellt. Dieses Kollektiv stellt eine repräsentative Stichprobe dar, aus welcher auf die Grundgesamtheit der schilddrüsengesunden $\mathrm{Be}-$ völkerung des Raumes Berlin (West) geschlossen werden kann.

Die Probanden mußten aufgrund der Versuchsplanung folgende Kriterien erfüllen, um in das Referenzkollektiv aufgenommen zu werden:

1. Ausgewogene Altersverteilung zwischen dem 18. und 64. Lebensjahr.

\section{Schilddrüsengesundheit.}

3. Die Probanden durften keine Faktoren aufweisen, die zu einer Beeinflussung der Schilddrüsenhormonparameter führen können.

Folgende diagnostische Maßnahmen wurden bei jedem Probanden durchgeführt:

\section{Anamnèse.}

2. Körperliche Untersuchung.

3. Laborchemische Parameter.

Neben einer umfangreichen schilddrüsenspezifischen Anamnese wurde besonderer Wert auf Nebenerkrankungen, Medikamente und gynäkologische Aspekte, soweit für die Schilddrüsendiagnostik von Bedeutung, gelegt. Die körperliche Untersuchung beinhaltete die Palpation der Schilddrüse, die Messung des Blutdruckes und der Herzfrequenz. Der allgemeine Aspekt des Probanden wurde beurteilt, mit Berücksichtigung der Hautbeschaffenheit und einer eventuellen Augensymptomatik. Es wurde auf Einflußstauung, Heiserkeit und Tremor geachtet.

Um Probanden mit Erkrankungen, welche die Schilddrüsenhormonparameter beeinflussen können, zu erfassen, wurden routinemäßig folgende laborchemische Parameter bestimmt:

1. Blutbild mit Differentialblutbild.

2. Leberspezifische Enzyme (GPT, $\gamma$ GT).

3. Fettstoffwechsel (Cholesterin, Triglyceride).

4. Gesamteiweiß und Elektrophorese.

5. Immunglobuline.

Palpatorische Strumabefunde wurden mittels Sonographie kontrolliert. Bei klinischem Verdacht auf eine Hyperbzw. Hypothyreose ist dem Probanden ein TRH-Test empfohlen und das Ergebnis berücksichtigt worden. Aufgrund möglicher Nebenwirkungen hielten wir es nicht für vertretbar, bei gesunden Probanden routinemäßig einen TRH-Test durchzuführen. Die Untersuchung wurde so geplant, daß im Gesamtkollektiv eine in etwa gleichmäBige Alters- und Geschlechtsverteilung herrschte. Insgesamt wurden 236, davon 138 weibliche und 98 männliche Probanden im Alter zwischen 18 und 64 Jahren untersucht.

Von den 236 Probanden konnten 57 Probanden (37 weibliche, 20 männliche) nicht in die statistische Auswertung einbezogen werden, weil sie den von uns definierten Kriterien eines schilddrüsengesunden Kollektivs nicht entsprachen.

Die Tab. 1 zeigt als Übersicht die zahlenmäßige Zusammensetzung des Gesamtprobandenkollektivs, der ausge-

Tab. 1: Aufgliederung der Probanden

\begin{tabular}{lc}
\hline Gesamtprobandenzahl & 236 \\
\hline weibliche Probanden & 138 \\
männliche Probanden & 98
\end{tabular}

Ausgeschlossene Probanden $\quad 57$

weibliche Probanden 37

männliche Probanden $\quad 20$

Euthyreosekollektiv

179

weibliche Probanden

ohne hormonelle Kontrazeption

weibliche Probanden

mit hormoneller Kontrazeption

männliche Probanden 
schlossenen Probanden und des verbliebenen Euthyreosekollektivs.

\subsection{Blutentnahme und Weiterverarbeitung der Blutproben}

Die Blutentnahme, der Abnahmezeitpunkt, die Weiterbearbeitung und Bestimmungen der Blutproben wurden unter standardisierten Bedingungen durchgeführt.

Es wurden bei jedem Probanden $25 \mathrm{ml}$ Blut durch Punktion einer kurz gestauten peripheren Unterarmvene entnommen. In Anpassung an die Bedingungen ambulanter Untersuchungsstellen wurde die Abnahme in sitzender Körperposition durchgeführt. Es muß beachtet werden, daß es aufgrund der extravasalen/intravasalen Flüssigkeitsverschiebungen bei unterschiedlichen Körperpositionen zu verschiedenen Konzentrationen der zu bestimmenden Parameter kommen kann (20). Eine weitere Vorbedingung war, daß 12 Std. vor der Entnahme kein Fett mehr gegessen und am Untersuchungstag selbst auf Tee, Kaffee und Nikotin verzichtet wurde.

Es ist bekannt, daß Schilddrüsenhormone tageszeitlichen

Schwankungen unterworfen sind. Z. B. wurden für basale TSH (Thyreoidea stimulierendes Hormon) in der Nacht deutlich höhere Werte ermittelt als am Tage $(1,14,28)$. Nicht so deutlich sind die Resultate bezüglich T3 (Trijodthyronin) und T4 (Thyroxin) $(2,14,16,28)$. Spitzenwerte für T3 und T4 wurden gegen 9.00 Uhr gemessen (2). Obwohl die tageszeitlichen Fluktuationen relativ gering sind und für die Routinediagnostik wahrscheinlich keine Relevanz haben, wurde die circadiane Periodik durch eine beschränkte Blutabnahmezeit zwischen $8.30 \mathrm{Uhr}$ und 11.00 Uhr berücksichtigt. Nach Entnahme wurde das Init Vollblut zentrifugiert, das gewonnene Serum jedes $\mathrm{Pa}$ igt: tienten gepoolt, auf Aliquots verteilt und bis zur Analyse 此: bei $-35^{\circ} \mathrm{C}$ tiefgefroren. Ein Teil der Proben wurde tiefgeBühlt an auswärtige Labors versandt.

\section{Bestimmungen der Schilddrüsenparameter}

\subsection{Schilddrüsenparameter und ihre Bestimmungs- methoden (Tab. 2)}

Für folgende Schilddrüsenhormonparameter wurden im Rahmen dieser Arbeit Referenzwertbereiche aufgestellt:

Die Proteinbindungskapazität der Schilddrüsenhormone wurde durch Bestimmung des TBG (Thyroxin-bindendes Globulin) und der $\mathrm{T}_{3}$-uptake ermittelt.

Es wurden die Gesamthormonkonzentrationen des T4 und des T3 bestimmt. Die freien, biologisch aktiven Schilddrüsenhormone (fT3, fT4) wurden auf direktem und indirektem Wege erfaßt. Zur indirekten Bestimmung wurden die T4/TBG- und T3/TBG-Quotienten, ferner der fT4-Index als Parameter benutzt. Der fT4-Index errechnet sich durch Multiplikation der T4-Konzentration mit der T3-uptake-Ratio.

Ferner wurde das hypophysär gebildete und die Schilddrüse stimulierende Hormon TSH und die biologisch inaktive Form des T3, das reverse T3 (rT3) bestimmt.

\section{Statistische Auswertung}

Wie im Diskussionsteil beschrieben, kann man für die meisten biologischen Merkmale nicht das Vorliegen einer Normalverteilung voraussetzen. Deshalb wurden die verschiedenen Parameter der Gesamtpopulationen bzw. der Subpopulationen mit Hilfe des Kolmogoroff-SmirnoffTests auf das Vorliegen einer Normalverteilung geprüft. Dabei ergaben sich für die einzelnen Merkmale (Schilddrüsenhormonparameter) bei den verschiedenen Populationen folgende Resultate:

Männer:

Signifikante Abweichung von der Normalverteilung bei allen Merkmalen.

Tab. 2: Bestimmungsverfahren der Schilddrüsenparameter, die verwendeten Test-Kits und deren Präzision (Interassay-Varianz)

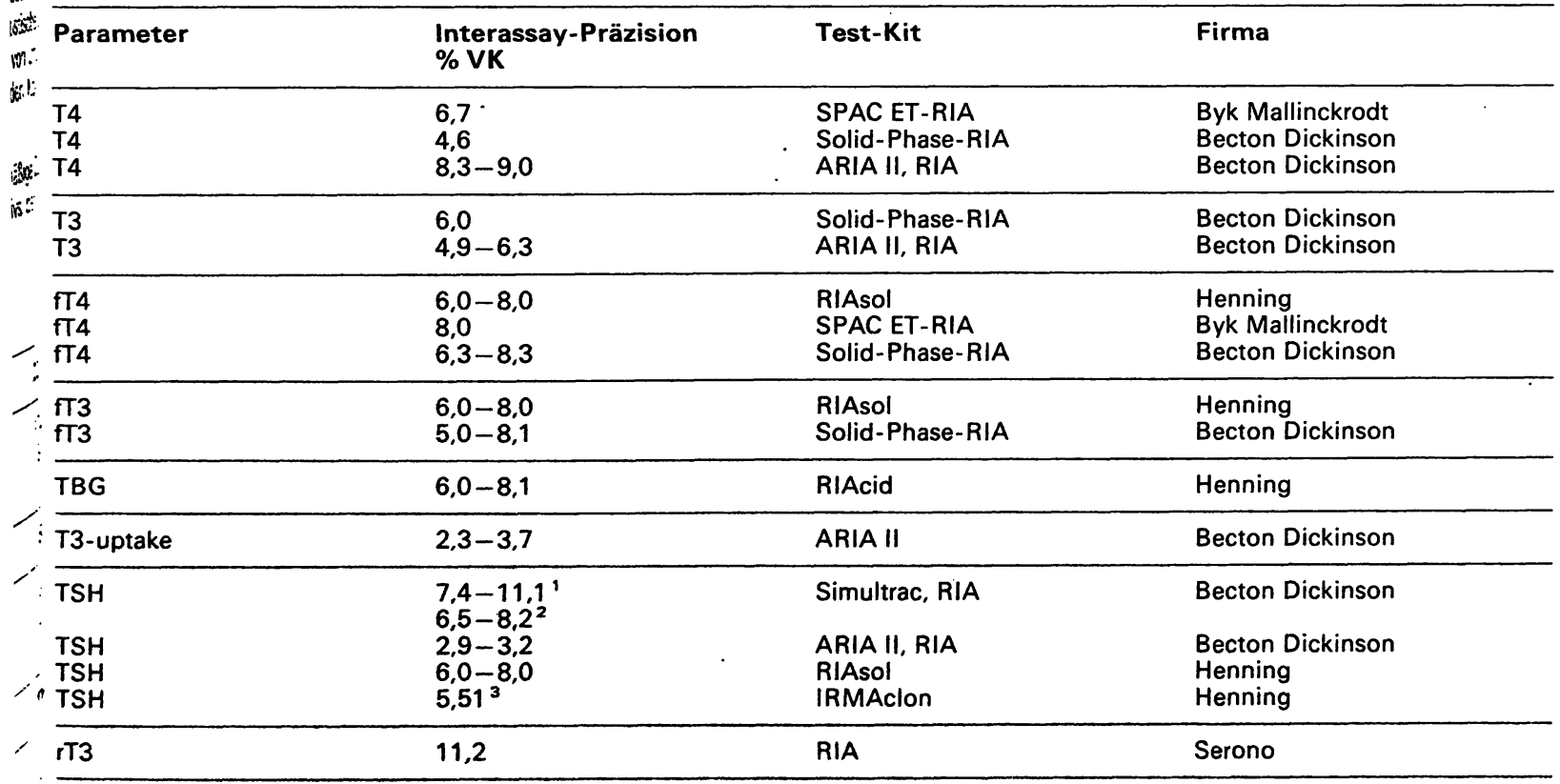

ISH 2-Stunden-Assay.

2 TSH 4-Stunden-Assay.

3 Im eigenen Labor Ermittelt. 


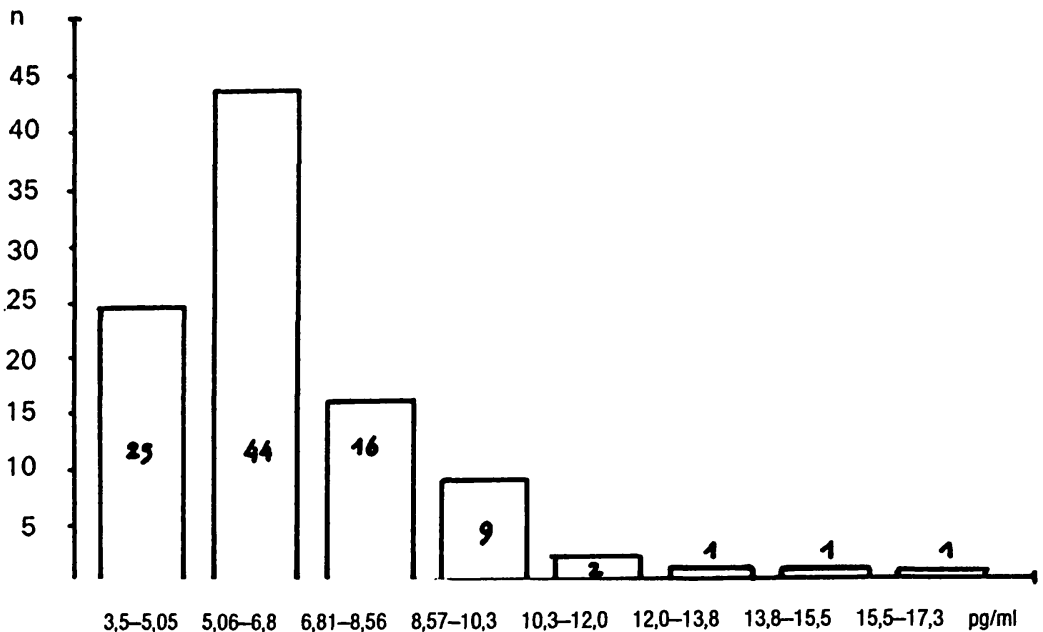

Gesamtfrauenkollektiv:

Signifikante Abweichung von der Normalverteilung bei allen Merkmalen.

Frauen ohne hormonelle Kontrazeption:

Außer fT4 (Byk Mallinckrodt) signifikante Abweichung von der Normalverteilung bei allen Merkmalen.

Frauen mit hormoneller Kontrazeption:

Aufgrund eines zu geringen Stichprobenumfanges wurde kein statistischer Test durchgeführt.

Da für die einzelnen Schilddrüsenhormon-Parameter keine Normalverteilungen vorliegen, wurden folglich für die Erstellung der Referenzwerte verteilungsfreie Parameter wie Median und Perzentile berechnet. Abweichungen von der Normalverteilung für Schilddrüsenhormone wurden schon früher gefunden $(10,17)$. Abb. 1 zeigt exemplarisch für fT3 die Abweichung von der Normalverteilung.

Neben der geschlechtsspezifischen deskriptiven Statistik wurden auch statistische Vergleiche auf Geschlechtsunterschiede durchgeführt (parameterfreier Zweistichprobentest nach Mann und Whitney). Die Überprüfung etwaiger Unterschiede in den Altersklassen erfolgte mit dem parameterfreien $\mathrm{H}$-Test für mehr als zwei unabhängige Stichproben nach Kruskal und Wallis (22).

Als Signifikanzniveau wurden folgende Irrtumswahrscheinlichkeiten zugrunde gelegt:

* $0,05 \geq p>0,01$

** $0,01 \geq p>0,001$

*** $0,001 \geq p$.

\section{Ergebnisse und Diskussion}

Um aus der Analyse von Blutproben pathophysiologische Zustände zu erkennen, ist es üblich, sogenannte Normalwerte bzw. Normbereiche zu erstellen. Obwohl dieser Begriff tagtäglich verwendet wird, sucht man vergeblich in den Lehrbüchern der Medizin über eine gründliche Analyse der Begriffe normal, Normalität und Norm. Die Folge davon ist, daß im medizinischen Sprachgebrauch diese Begriffe oft ungenau und darüber hinaus zweideutig benutzt werden, einmal im mathematischen Sinne als Ausdruck einer statistischen Normalverteilung, zum anderen als Synonym für Gesundheit (24). Bei den meisten der vorliegenden Untersuchungen, die sich mit dieser auf Schilddrüsenhormonparameter bezogenen Problematik beschäftigen, wurden entweder nur das arithmetische Mittel $(\bar{x})$ oder der $\bar{x} \pm 2 s$-Bereich als Normalbereich angegeben. Die Aufstellung von Normalwerten mit dieser Methode ist zwar in der Medizin weithin üblich, jedoch aus mehreren Gründen wissenschaftlich unkorrekt und führt nicht zuletzt deshalb auch oft zu unbrauchbaren Normalwerten. Denn die Angabe von $\bar{x} \pm 2$ s als Normalwertbereich und die davon abhängige Interpretation setzen eine Normalverteilung der Schilddrüsenhormonparameter voraus. Diese restriktive Voraussetzung (Annahme einer Normalverteilung) gilt jedoch für die meisten biologischen Variablen nicht $(8,19)$ und ist auch für die Schilddrüsenhormonparameter nicht wahrscheinlich. Dennoch wird dies meist bei der Aufstellung von Normalwertbereichen stillschweigend, d.h. ohne Nachprüfung, vorausgesetzt. Die vorliegende Untersuchung ergab, daß die meisten Schilddrüsenhormonparameter nicht normalverteilt sind (s.o.). Wenn diese Schilddrüsenhormone als biologische Variablen aber nicht normal verteilt sind, sagt die Standardabweichung (s) wenig oder gar nichts über die interindividuelle Variation dieser Variablen aus. Ebenso ist das arithmetische Mittel nicht mehr notwendigerweise ein repräsentatives Lokalisationsmaß für eine beliebige Verteilung. Bei der vorliegenden Untersuchung wurden daher die 2,5- bzw. 97,5-Perzentile berechnet und der daraus resultierende $95 \%$-Interperzentilbereich entsprechend dem 2-s-Bereich einer Normalverteilung als Referenzbereich festgelegt.

$\mathrm{Zu}$ dem rein mathematischen Problem der Bestimmung der Normbereiche gesellt sich allerdings auch noch folgende Problematik, die aus der Schwierigkeit der Definition des "Normalen" resultiert: Der Begriff „Normalbereich" impliziert einen in einer Skala abgegrenzten Bezirk, dessen Überschreitung nach beiden Seiten nicht nur eine quantitative Veränderung bedeutet, sondern etwas Qualitatives, nämlich den Übergang vom Gesunden zum Kranken (24). Da die Abgrenzung (normal - nicht normal) aus der Untersuchung eines einzigen gesunden Kollektivs und aus der Berechnung des arithmetischen Mittels bzw. des Medians und der Standardabweichung bzw. des Interperzentilbereiches erfolgt, ließe sich allein mit Hilfe mathematischer Methoden der Zustand „krank - ge- 


\section{Bei Licht besehen (3)}

Am Anfang war das Licht...

Mit dem Licht beginnt die geordnete und lebendige Welt. Das Licht hat Forscher und Wissenschaftler schon immer fasziniert. Ihre Entdeckungen und Entwicklungen haben unser Leben revolutioniert. Die Steuerung und

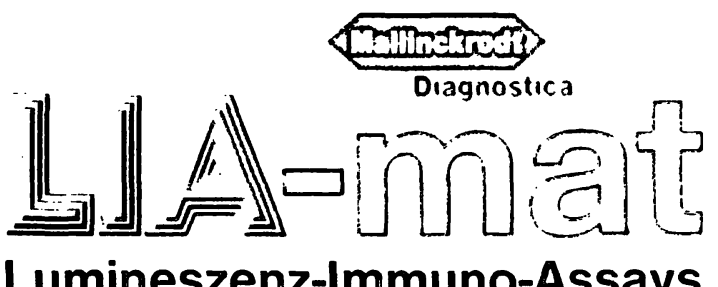

Nutzbarmachung von Licht stellt für jede Generation eine Herausforderung an ihr wissenschaftlich-innovatives Denken dar.

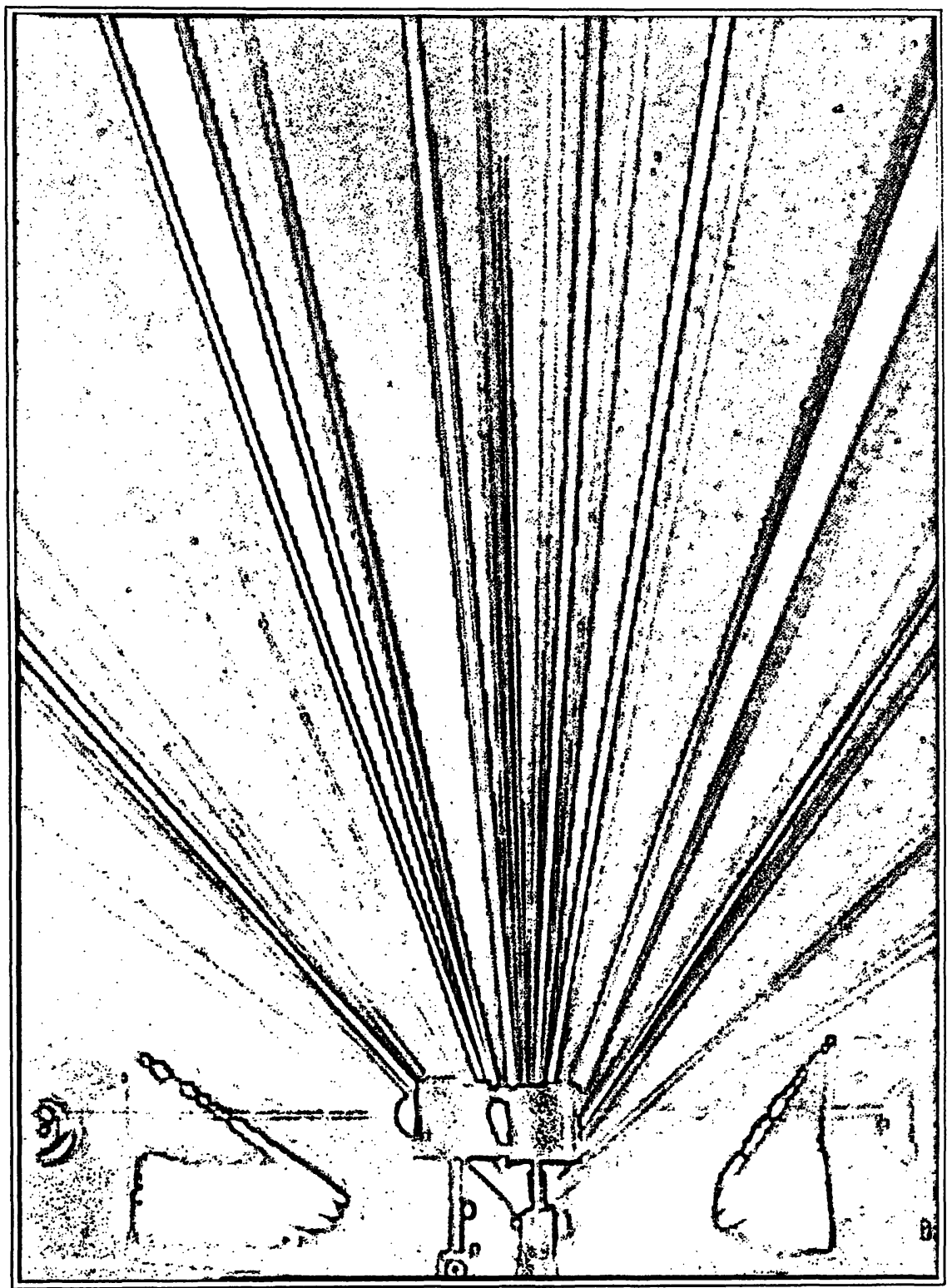

Poster auf Anfrage

kostenlos erhältlich

(Stichwort: LIA-mat 3)

1960 Theodore H. Maiman

entwickelt eine neuartige Lichtquelle:

LASER - Light Amplification by Stimulated

Emission of Radiation. Eine neue Ära der

Nutzung von Licht in der Medizin beginnt.
1987 Mallinckrodt Diagnostica

stellt LIA-mat" Lumineszenz-ImmunoAssays vor. Chemisch erzeugte Lichtsignale eröffnen neue Wege und Perspektiven in der Labor-Diagnostik. 


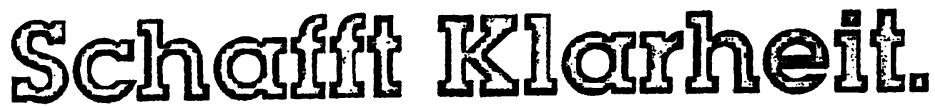

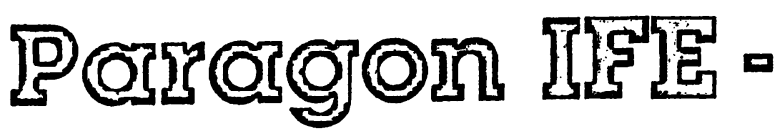 die Imnunfizarion won Beclman.}

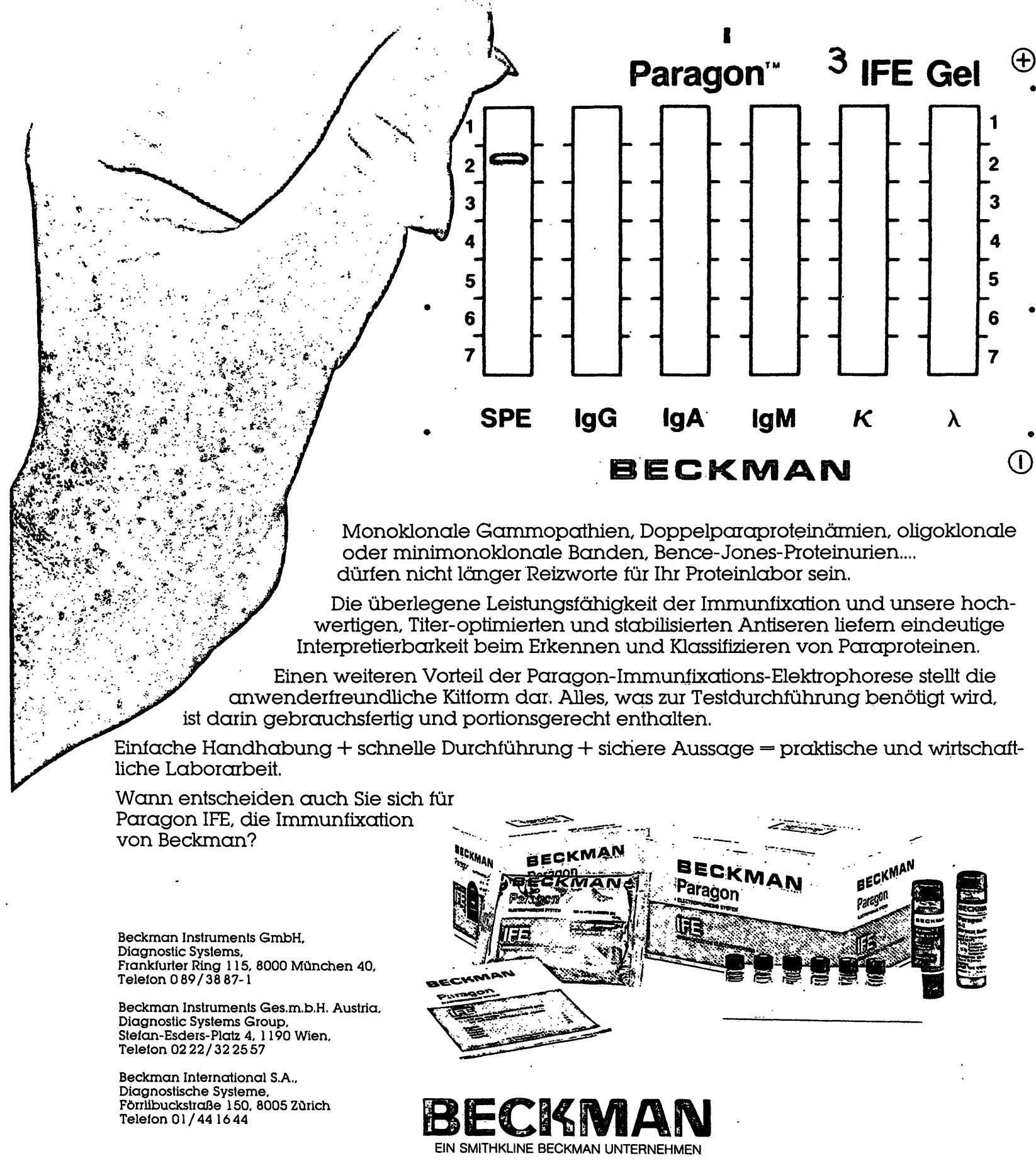


sund" erfassen. Das hieße: "Normüberschreitungen definieren, was krank ist, und nicht die Krankheit, wann eine Normgrenze überschritten wurde" (24). Die mathematische Festlegung des Normbereiches mittels doppelter Standardabweichung oder entsprechende Perzentile ist jedoch in jedem Falle eine willkürliche Festlegung, die auf die Definition des "Gesunden - Kranken" keine Rücksicht nimmt. Aber auch andere Überlegungen zur Definition des Normalbereiches stoßen auf Schwierigkeiten. Postuliert man beispielsweise, daß ein Meßwert als "normal“" bezeichnet wird, wenn er in Grenzen liegt, welche erfahrungsgemäß mit der Abwesenheit von Mißempfindungen oder Störungen einhergehen (24), „dann begibt man sich völlig in den Bereich des Subjektiven“. Mißempfindungen oder Störungen, die wir als Krankheiten bezeichnen, werden interindividuell, aber auch in- traindividuell, z.B. zu verschiedenen Zeitpunkten, sehr unterschiedlich gewichtet (24). Aufgrund dieser Schwierigkeiten wurde in der Klinischen Chemie anstelle des "Normalwertes" der Begriff „Referenzbereich" eingeführt $(7,26)$.

Der Begriff Referenzbereich stellt lediglich ein Bezugssystem dar, das mit statistischen Methoden an einer gesunden Population gewonnen wurde. Eine Überschreitung dieses Bezugsbereiches durch bestimmte gemessene Werte impliziert nicht den Begriff des Pathologischen, während umgekehrt ein Meßwert, der sich innerhalb des Bezugsbereiches befindet, nicht unbedingt mit dem Begriff „normal“ verknüpft ist. In diesem Sinne wurden die vorliegenden Populationen und Subpopulationen ausgewertet.

Tab. 3: Vergleich des Frauenkollektivs ohne hormonelle Kontrazeption $\left(n_{1}\right)$ mit dem Männerkollektiv $\left(n_{2}\right)$ bezüglich signifikanter Geschlechtsabhängigkeiten.

In der ersten Spalte sind die Schilddrüsenparameter mit Angabe der Maßeinheiten aufgelistet. In der zweiten Spalte folgen die jeweiligen Firmen. In den folgenden Spalten sind die jeweiligen Medianwerte $(\bar{x})$, Percentilbereiche $\left(P_{2.5}-P_{97.5}\right)$ und der dazugehörigen Stichprobenumfang $(n)$ angegeben. In der letzten Spalte sind die Signifikanzniveaus angegeben

\begin{tabular}{|c|c|c|c|c|c|c|c|c|}
\hline \multirow{2}{*}{$\begin{array}{l}\text { Schild- } \\
\text { drüsen- } \\
\text { parameter }\end{array}$} & \multirow[t]{2}{*}{ Firmen } & \multicolumn{7}{|c|}{ statistische Ergebnisse } \\
\hline & & $\tilde{\mathbf{x}}_{1}$ & $P_{2.5}-P_{97.5}$ & $\left(n_{1}\right)$. & $\tilde{\mathbf{x}}_{2}$ & $P_{2.5}-P_{97.5}$ & $\left(\mathbf{n}_{2}\right)$ & \\
\hline \multirow{4}{*}{$\begin{array}{l}\text { TSH } \\
(\mathrm{mU} / \mathrm{ml})\end{array}$} & Henning (IRMA) & 1,10 & $0,32-4,17$ & $(66)$ & 1,17 & $0,27-2,68$ & $(76)$ & NS \\
\hline & Henning (RIA) & 1,61 & $0,30-5,40$ & $(67)$ & 1,54 & $0,28-4,30$ & $(77)$ & NS \\
\hline & Becton Dickinson & 2,39 & $1,55-5,71$ & $(67)$ & 2,38 & $1,50-3,72$ & $(74)$ & NS \\
\hline & Becton D. (ARIA II) & 1,48 & $0,50-4,53$ & $(66)$ & 1,60 & $0,50-3,92$ & $(78)$ & NS \\
\hline \multirow{3}{*}{$\begin{array}{l}\text { T4 } \\
(\mu g / d l)\end{array}$} & Byk Mallinckrodt & 7,92 & $5,72-10,7$ & $(68)$ & 8,10 & $5,77-11,0$ & (78) & NS \\
\hline & Becton Dickinson & 8,05 & $5,60-11,7$ & $(54)$ & 7,95 & $5,56-10,7$ & $(54)$ & NS \\
\hline & $\begin{array}{l}\text { Becton Dickinson } \\
\text { (ARIA II) }\end{array}$ & 7,60 & $4,50-10,3$ & $(66)$ & 7,34 & $5,22-9,63$ & $(77)$ & NS \\
\hline fT4-Index & Becton D. (ARIA II). & 7,21 & $4,56-8,74$ & $(62)$ & 6,94 & $5,07-9,12$ & $(75)$ & NS \\
\hline \multirow{3}{*}{$\frac{T 4}{T B G} \cdot 10^{-3}$} & Byk Mallinckrodt & 3,43 & $1,87-5,09$ & $(67)$ & 3,76 & $2,28-5,32$ & $(77)$ & $*$ \\
\hline & Becton Dickinson & 3,58 & $1,92-5,00$ & $(53)$ & 3,58 & $2,30-4,74$ & $(54)$ & NS \\
\hline & Becton D. (ARIA II) & 3,15 & $1,68-5,78$ & $(65)$ & 3,46 & $2,02-4,89$ & $(77)$ & NS \\
\hline \multirow{3}{*}{$\begin{array}{l}\text { fT4 } \\
\text { (ng/dl) }\end{array}$} & Henning & 1,61 & $1,26-2,16$ & $(67)$ & 1,65 & $1,28-1,90$ & $(77)$ & NS \\
\hline & Byk Mallinckrodt & 1,09 & $0,85-1,36$ & $(68)$ & 1,18 & $0,89-1,42$ & $(78)$ & $\cdot$ \\
\hline & Becton Dickinson & 1,01 & $0,73-1,41$ & $(60)$ & 1,14 & $0,84-1,39$ & $(67)$ & $\cdots$ \\
\hline \multirow{2}{*}{$\begin{array}{l}\text { T3 } \\
\text { (ng/dl) }\end{array}$} & Becton Dickinson & 126 & $86,2-166$ & $(42)$ & 125 & $73,0-166$ & $(46)$ & NS \\
\hline & Becton D. (ARIA II) & 150 & $98,2-212$ & $(62)$ & 154 & $103-211$ & $(75)$ & NS \\
\hline \multirow{2}{*}{$\frac{T 3}{T B G} \cdot 10^{-5}$} & Becton Dickinson & 5,23 & $3,03-9,05$ & $(42)$ & 5,50 & $3,82-7,94$ & $(46)$ & NS \\
\hline & Bect. D. (ARIA II) & 6,78 & $2,83-11,2$ & $(61)$ & 7,21 & $3,99-11,6$ & $(75)$ & NS \\
\hline \multirow{2}{*}{$\begin{array}{l}\mathrm{fT} 3 \\
(\mathrm{pg} / \mathrm{ml})\end{array}$} & Henning & 5,40 & $3,36-7,90$ & $(66)$ & 6,22 & $3,96-8,62$ & $(75)$ & $\cdots$ \\
\hline & Becton Dickinson & 5,22 & $3,99-6,42$ & $(66)$ & 5,90 & $4,42-7,08$ & $(69)$ & $\cdots$ \\
\hline rT3 & Serono & 20,5 & $13,4-35,2$ & $(65)$ & 22,3 & $13,9-31,5$ & $(74)$ & $\cdot$ \\
\hline $\begin{array}{l}\text { TBG } \\
(\mathrm{mg} / \mathrm{l})\end{array}$ & Henning & 24,3 & $\begin{array}{c}12,5-41,9 \\
.\end{array}$ & $(67)$ & 21,5 & $13,2-31,4$ & $(77)$ & NS \\
\hline $\begin{array}{l}\text { T3-uptake } \\
\text { (\%) }\end{array}$ & Becton D. (ARIA II) & 27.9 & $23,0-33,4$ & $(62)$ & 28,6 & $24,3-33,1$ & $(75)$ & NS \\
\hline
\end{tabular}


1. Geschlechtsabhängigkeiten der Schilddrüsenhormonparameter

Bezüglich bestehender Geschlechtsunterschiede der Schilddrüsenhormonparameter erbrachte die WickhamStudie (5), welche einen sehr hohen Stichprobenumfang aufweist ( $n=2779)$, folgende Resultate: Unter Ausschluß von Schilddrüsenhormonparameter beeinflussenden Größen, z.B. Medikationen (Ovulationshemmer), zeigten sich bei Frauen signifikant höhere Gesamt-T4und TBG-Konzentrationen im Serum als bei Männern. Am deutlichsten differierten die T4-Spiegel in der Altersgruppe vom 18. - 35. Lebensjahr. Für die Gesamt-T3Konzentrationen konnten bei Männern bis etwa zum 50. Lebensjahr höhere Serumspiegel bestimmt werden.

Auch die Untersuchung von Burr und Mitarb. (3) zeigte bei Frauen signifikant höhere TBG-Konzentrationen als bei Männern. Ergebnisse von Kojima und Mitarb. (12) ergaben signifikant höhere TBG-Konzentrationen bei Frauen in der vierten Dekade.

Andere Autoren hingegen konnten keine geschlechtsspezifischen Änderungen finden $(18,21)$.

Die vorliegende Arbeit (Tab.3) bestätigt die Resultate von Pickart und Mitarb. (18) und Rootwelt und Mitarb. (21) bezüglich des TBG bzw. T3-uptake und der Gesamthormonkonzentrationen T4 und T3. Hier konnten keine signifikanten Geschlechtsunterschiede registriert werden. Das heißt, nach sorgfältigem Ausschluß von hyperöstrogenen Zuständen (z. B. hormonelle Kontrazeption), ergaben sich keine signifikanten Unterschiede in der Proteinbindungskapazität mit konsekutiven Gesamthormonverschiebungen zwischen Männern und Frauen.

Die freien Hormonkonzentrationen (fT3, fT4) zeigten allerdings bei direkter radioimmunologischer Bestimmung signifikante Unterschiede und damit eine deutliche $\mathrm{Ge}$ schlechtsabhängigkeit; die fT3- und fT4-Werte lagen bei Frauen ohne hormonelle Kontrazeption niedriger als im Männerkollektiv.

Mit der indirekten Bestimmung der freien Hormonkonzentrationen mittels T4:TBG- bzw. T3:TBG-Quotienten konnten diese Veränderungen nicht so deutlich gezeigt werden. Die Werte lagen zwar im Frauenkollektiv durchweg wie bei der direkten Bestimmung niedriger als im Männerkollektiv, ein signifikanter Unterschied konnte al- lerdings nur mit dem T4:TBG-Quotienten von Byk Mallinckrodt aufgedeckt werden. Auch der fT4-Index zeigte keine signifikanten Unterschiede.

Rootwelt und Mitarb. (21) fanden weder bei direkter $\mathrm{Be}$ stimmung (fT4-RIA), noch bei indirekter Bestimmung (T4:TBG, fT4-Index) eine signifikante Geschlechtsabhängigkeit. Für das reverse T3 konnte im Rahmen dieser Arbeit eine Geschlechtsabhängigkeit gezeigt werden. Die Werte lagen im Männerkollektiv signifikant höher als im Frauenkollektiv.

Auch über Geschlechtsabhängigkeiten des basalen TSH und der TSH-Antwort nach Stimulation mit TRH liegen zahlreiche Ergebnisse vor. So wird bei in etwa vergleichbaren basalen TSH-Werten bei Frauen eine signifikant höhere TSH-Antwort auf TRH als bei Männern beschrieben $(6,13,23,27)$.

Im Rahmen dieser Arbeit wurde mit vier verschiedenen Radioimmunoassays der basale TSH-Wert bestimmt. Die Resultate (Tab. 3) bestätigen die in der Literatur beschriebenen Beobachtungen. Beim Vergleich des Männerkollektivs mit dem Kollektiv der Frauen ohne hormonelle Kontrazeption zeigten sich keine geschlechtsabhängigen Unterschiede. Um den Östrogeneinfluß darzustellen, wurden die Kollektive Frauen ohne und Frauen mit hormoneller Kontrazeption auf signifikante Unterschiede hin miteinander verglichen (Tab.4). Wie erwartet und in der Literatur beschrieben, zeigte der Östrogeneinfluß in der Gruppe mit hormoneller Kontrazeption eine signifikant höhere Proteinbindungskapazität und damit auch der $\mathrm{Ge}$ samthormonkonzentrationen (T4 und T3). Auch die direkten Bestimmungen der freien Hormonkonzentrationen (fT4 und fT3) zeigten die in der Literatur einheitlich beschriebenen Veränderungen, nämlich konstante östrogenunabhängige fT4- und fT3-Werte.

Die indirekten Bestimmungsmethoden der freien Hormonkonzentrationen hingegen konnten diese Resultate nicht bestätigen. Sowohl die T4:TBG-Quotienten, als auch die T3:TBG-Quotienten zeigten bei allen in dieser Arbeit verwendeten Methoden signifikant niedrigere Werte im Kollektiv mit hormoneller Kontrazeption, sprich bei Östrogeneinfluß. Der fT4-Index gibt dementsprechend einen höheren Wert an. Als mögliche Erklärung dieser diskrepanten Resultate könnte folgendes gelten:

Tab. 4: Vergleich des Frauenkollektivs ohne hormonelle Kontrazeption $\left(n_{1}\right)$ mit dem Frauenkollektiv mit hormoneller Kontrazeption $\left(n_{2}\right)$. Weitere Angaben wie in Tab. 3

\begin{tabular}{|c|c|c|c|c|c|c|c|c|}
\hline \multirow{2}{*}{$\begin{array}{l}\text { Schild- } \\
\text { drüsen- } \\
\text { parameter }\end{array}$} & \multirow[t]{2}{*}{ Firmen } & \multicolumn{7}{|c|}{ statistische Ergebnisse } \\
\hline & & $\tilde{\mathbf{x}}_{1}$ & $P_{2.5}-P_{97.5}$ & $\left(n_{1}\right)$ & $\tilde{\mathbf{x}}_{2}$ & $\mathbf{P}_{2,5}-\mathbf{P}_{97,5}$ & $\left(n_{2}\right)$ & \\
\hline \multirow{3}{*}{$\begin{array}{l}\text { T4 } \\
(\mu g / d l)\end{array}$} & Byk Mallinckrodt & 7,92 & $5,72-10,7$ & (68) & 10,5 & $7,40-14,5$ & (33) & *.* \\
\hline & Becton Dickinson & 8,05 & $5,60-11,7$ & (54) & 9,93 & $5,60-14,1$ & (27) & $\cdots$ \\
\hline & Becton D. (ARIA II) & 7,60 & $4,50-10,3$ & $(66)$ & 10,2 & $6,50-12,3$ & (33) & $\cdots$ \\
\hline \multirow{2}{*}{$\begin{array}{l}\text { T3 } \\
\text { (ng/dl) }\end{array}$} & Becton Dickinson & 126 & $86,2-166$ & $(42)$ & 157 & $104-247$ & $(24)$ & $\cdots$ \\
\hline & Becton D. (ARIA II) & 150 & $98,2-212$ & $(62)$ & 174 & $126-234$ & $(32)$ & $* *$ \\
\hline $\begin{array}{l}\text { rT3 } \\
\text { (ng/dl) }\end{array}$ & Serono & 20,5 & $13,4-35,2$ & (65) & 24,5 & $16,2-37,3$ & (33) & $\cdots$ \\
\hline \multirow{2}{*}{$\begin{array}{l}\text { TBG } \\
\text { (mg/l) } \\
\text { T3-uptake } \\
\text { (\%) }\end{array}$} & Henning & 24,3 & $12,5-41,9$ & (67) & 38,1 & $20,2-59,4$ & $(33)$ & $\cdots$ \\
\hline & Becton D. (ARIA II) & 27,9 & $23,0-33,4$ & $(62)$ & 24,0 & $18,0-30,2$ & $(32)$ & $\cdots$ \\
\hline
\end{tabular}


Es liegt möglicherweise keine absolut parallel ablaufende Verschiebung der Proteinbindungskapazität und der $\mathrm{Ge}$ samthormone unter Östrogeneinfluß vor. Folglich sind die indirekten Bestimmungsmethoden nicht in der Lage, diesen Fehler zu kompensieren und den euthyreoten Funktionszustand zu dokumentieren.

\section{Altersabhängigkeiten der Schilddrüsenhormonparameter}

Für das Kindes- und Jugendalter werden die GesamtT4- und Gesamt-T3-Konzentrationen in relativer Übereinstimmung als erhöht angegeben. Über den Grad der Erhöhung schwanken die Angaben in der Literatur allerdings erheblich $(9,11,25,27)$. Im Erwachsenenalter (20. - 60. Lebensjahr) konnten in relativer Übereinstimmung, bei sorgfältigem Ausschluß von extrathyreoidalen
Nebenerkrankungen, keine signifikanten und diagnostisch relevanten Altersabhängigkeiten aufgedeckt werden $(4,9,12,18,21,25,27)$.

Abschließend bleibt allerdings anzumerken, daß die $\mathrm{Ge}$ samtheit dieser Resultate sehr kritisch betrachtet werden muß, da sie Ergebnisse von Querschnittsstudien darstellen. Den wissenschaftlich exakten, allerdings technisch kaum realisierbaren Weg, um reine Altersunabhängigkeiten aufzudecken, stellt die Longitudinalstudie dar (9). Im Rahmen dieser Arbeit wurde ein Erwachsenenkollektiv, welches sich zwischen dem 20. und 65. Lebensjahr bewegte, untersucht. Die Ergebnisse dieser Arbeit (Tab.5, 6) bestätigen weitgehend die in der Literatur beschriebenen Resultate. Im Gegensatz zu den meisten vorliegenden Arbeiten wurde bei unserer statistischen Auswertung kein Gesamtkollektiv betrachtet, sondern die Altersabhängigkeiten separat für die beiden Kollektive Männer und

Tab. 5: Altersabhängigkeiten innerhalb des Frauenkollektivs ohne hormonelle Kontrazeption $\left(n_{1}=20-29 \mathrm{~J} . ; n_{2}=30-39 \mathrm{JH} . ; n_{3}=\right.$ $40-49 \mathrm{~J} . ; n_{4}$ über $50 \mathrm{~J}$.) Weitere Angaben wie in Tab. 3

\begin{tabular}{|c|c|c|c|c|c|c|c|c|c|c|}
\hline \multirow{2}{*}{$\begin{array}{l}\text { Schild- } \\
\text { drüsen- } \\
\text { Parameter }\end{array}$} & \multirow[t]{2}{*}{ Firmen } & \multicolumn{9}{|c|}{ statistische Ergebnisse } \\
\hline & & $\tilde{\mathbf{x}}_{1}$ & $\left(n_{1}\right)$ & $\tilde{\mathbf{x}}_{2}$ & $\left(n_{2}\right)$ & $\tilde{\mathbf{x}}_{3}$ & $\left(n_{3}\right)$ & $\tilde{\mathbf{x}}_{4}$ & $\left(n_{4}\right)$ & \\
\hline \multirow{4}{*}{$\begin{array}{l}\text { TSH } \\
(\mathrm{mU} / \mathrm{ml})\end{array}$} & Henning (IRMA) & 1,15 & (15) & 1,14 & (23) & 1,44 & (19) & 0,89 & (9) & NS \\
\hline & Henning (RIA) & 1,60 & (15) & 1,63 & (23) & 2,45 & $(20)$ & 1,07 & (9) & NS \\
\hline & Becton Dickinson & 2,33 & (15) & 2,31 & $(24)$ & 2,39 & (19) & 2,61 & (9) & NS \\
\hline & Becton D. (ARIA II) & 1,65 & $(14)$ & 1,52 & $(24)$ & 1,35 & $(20)$ & 0,95 & $(8)$ & NS \\
\hline \multirow{3}{*}{$\begin{array}{l}\mathrm{T4} \\
(\mu \mathrm{g} / \mathrm{dl})\end{array}$} & Byk Mallinckrodt & 7,97 & $(15)$ & 7,85 & $(24)$ & 7,85 & $(20)$ & 8,60 & $(9)$ & NS \\
\hline & Becton Dickinson & 8,10 & (11) & 7,70 & (18) & 8,00 & $(16)$ & 8,60 & (9) & NS \\
\hline & Becton D. (ARIA II) & 7,25 & $(14)$ & 7,65 & $(24)$ & 7,85 & $(20)$ & 6,25 & $(8)$ & NS \\
\hline fT4-Index & Becton D. (ARIA II) & 6,85 & (23) & 7,30 & (23) & 7,25 & $(18)$ & 7,40 & (7) & NS \\
\hline \multirow{3}{*}{$\frac{T 4}{T B G} \cdot 10^{-3}$} & Byk Mallinckrodt & 3,09 & (15) & 3,02 & (23) & 3,61 & $(20)$ & 4,49 & (9) & NS \\
\hline & Becton Dickinson & 3,49 & (11) & 3,21 & (17) & 3,69 & $(16)$ & 4,33 & (9) & NS \\
\hline & Bect. D. (ARIA II) & 2,69 & (14) & 3,28 & (23) & 3,15 & $(20)$ & 3,06 & (8) & NS \\
\hline \multirow{3}{*}{$\begin{array}{l}\text { fT4 } \\
(\mathrm{ng} / \mathrm{dl})\end{array}$} & Henning & 1,62 & (15) & 1,58 & (23) & 1,60 & $(20)$ & 1,79 & (9) & NS \\
\hline & Byk Mallinckrodt & 1,05 & (15) & 1,10 & $(24)$ & $(1,08$ & $(20)$ & 1,18 & (9) & NS \\
\hline & Becton Dickinson & 0,96 & $(12)$ & 1,00 & $(23)$ & 0,99 & $(16)$ & 1,11 & $(9)$ & NS \\
\hline \multirow{2}{*}{$\begin{array}{l}\text { T3 } \\
(n g / d l)\end{array}$} & Becton Dickinson & 129 & (10) & 125 & $(14)$ & 120 & (13) & 156 & (5) & NS \\
\hline & Becton D. (ARIA II) & 153 & (14) & 143 & $(23)$ & 152 & $(18)$ & 149 & (7) & NS \\
\hline \multirow{2}{*}{$\frac{\mathrm{T} 3}{\mathrm{TBG}} \cdot 10^{-5}$} & Becton Dickinson & 4,73 & $(10)$ & 4,95 & $(14)$ & 6.01 & (13) & 5,70 & (5) & NS \\
\hline & Becton D. (ARIA II) & 5,94 & (14) & 5,91 & $(22)$ & 6,96 & (18) & 9,71 & $(7)$ & NS \\
\hline \multirow{2}{*}{$\begin{array}{l}\mathrm{fT3} \\
(\mathrm{pg} / \mathrm{ml})\end{array}$} & Henning & 5,90 & (15) & 5,45 & $(22)$ & 5,10 & $(20)$ & 4,97 & $(9)$ & NS \\
\hline & Becton Dickinson & 5,49 & (15) & 5,25 & (23) & 5,06 & (19) & 5,18 & (9) & NS \\
\hline $\begin{array}{l}\text { rT3 } \\
\text { (ng/dl) }\end{array}$ & Serono & 20,6 & (15) & 21,5 & (23) & 20,1 & (18) & 20,0 & (9) & NS \\
\hline $\begin{array}{l}\text { TBG } \\
(\mathrm{mg} / \mathrm{l})\end{array}$ & Henning & 25,3 & (15) & 25,5 & (23) & 19,9 & $(20)$ & 20,7 & (9) & NS \\
\hline $\begin{array}{l}\text { T3-uptake } \\
\text { (\%) }\end{array}$ & Becton Dickinson & 27,9 & (14) & 27,8 & (23) & 28,5 & $(18)$ & 27.0 & (7) & NS \\
\hline
\end{tabular}


Frauen ohne hormonelle Kontrazeption aufgestellt. Die Aufschlüsselung des Gesamtkollektivs ermöglicht eine genauere und differenziertere Aussage über die Altersabhängigkeiten, da bestehende Geschlechtsunterschiede als Einflußgröße ausscheiden. Für das Frauenkollektiv ohne hormonelle Kontrazeption konnte für keinen Parameter ein signifikanter Altersunterschied aufgedeckt werden (Tab.5).

Das Männerkollektiv (Tab.6) zeigte trotz sehr kleinem Stichprobenumfangs in der Altersklasse vom 50. - 65. Lebensjahr einen signifikant erniedrigten T3Wert an. Diese T3-Erniedrigung im Männerkollektiv wird übereinstimmend in der oben zitierten Literatur beschrieben. Während in der vorliegenden Untersuchung diese Altersabhängigkeit allerdings bereits in dem Kollektiv der 50-65jährigen Probanden auftrat, wird sie in der Literatur erst im Senium, d.h. ab dem 65. Lebensjahr beschrieben.

\section{Ergebnisse des Gesamteuthyreosekollektivs}

Tab. 7 zeigt die Referenzbereiche für das gesamte Euthyreosekollektiv, d.h. Männer, Frauen mit hormoneller Kontrazeption und Frauen ohne hormonelle Kontrazeption bilden ein gemeinsames Kollektiv. Aufgrund der oben beschriebenen, nur für wenige Schilddrüsenparameter gefundenen Alters- und Geschlechtsabhängigkeiten, erscheint es für die meisten Schilddrüsenparameter gerechtfertigt, Referenzbereiche aus diesem Gesamtkollektiv zu ermitteln. Durch den dadurch vergrößerten Stichprobenumfang $(n)$ sind die unvermeidlichen statistischen Fehler geringer (Fehler 2. Art). Dies gilt besonders für die alters- und geschlechtsunabhängigen basalen TSH-Werte.

Für die oben beschriebenen altersabhängigen T3-Werte und die geschlechtsabhängigen fT3- und fT4-Werte sollten ggf. die differenzierten Referenzbereiche beachtet werden.

Tab. 6: Altersabhängigkeiten innerhalb des Männerkollektivs. Weitere Angaben wie in Tab. 3

\begin{tabular}{|c|c|c|c|c|c|c|c|c|c|c|}
\hline \multirow{2}{*}{$\begin{array}{l}\text { Schild- } \\
\text { drüsen- } \\
\text { Parameter }\end{array}$} & \multirow[t]{2}{*}{ Firmen } & \multicolumn{5}{|c|}{ statistische Ergebnisse } & \multicolumn{4}{|l|}{. } \\
\hline & & $\tilde{\mathbf{x}}_{1}$ & $\left(n_{1}\right)$ & $\tilde{\mathbf{x}}_{2}$ & $\left(\mathbf{n}_{2}\right)$ & $\tilde{\mathbf{x}}_{3}$ & $\left(\mathbf{n}_{3}\right)$ & $\tilde{\mathbf{x}}_{4}$ & $\left(n_{4}\right)$ & \\
\hline \multirow{4}{*}{$\begin{array}{l}\text { TSH } \\
(\mathrm{mU} / \mathrm{ml})\end{array}$} & Henning (IRMA) & 1,34 & $(23)$ & 0,96 & $(0,25)$ & 1,20 & $(21)$ & 1,29 & $(7)$ & NS \\
\hline & Henning (RIA) & 1,70 & $(23)$ & 1,35 & $(26)$ & 1,60 & $(21)$ & 1,36 & (7) & NS \\
\hline & Becton Dickinson & 2,65 & $(23)$ & 2,24 & $(23)$ & 2,50 & $(21)$ & 2,11 & (7) & NS \\
\hline & Becton D. (ARIA II) & 2,20 & $(23)$ & 1,28 & $(26)$ & 1,70 & $(22)$ & 1,30 & (7) & NS \\
\hline \multirow{3}{*}{$\begin{array}{l}\text { T4 } \\
(\mu g / d l)\end{array}$} & Byk Mallinckrodt & 8,32 & $(23)$ & 8,10 & $\cdot(26)$ & 8,08 & $(22)$ & 7,00 & $(7)$ & NS \\
\hline & Becton Dickinson & 7,90 & $(19)$ & 8,10 & $(17)$ & 7,95 & $(14)$ & 6,70 & $(4)$ & NS \\
\hline & Becton D. (ARIA II) & 7,30 & $(23)$ & 7,38 & $(26)$ & 7,60 & $(21)$ & 6,60 & $(7)$ & NS \\
\hline fT4-Index & Becton D. (ARIA II) & 6,81 & $(23)$ & 7,15 & $(26)$ & 7,23 & $(21)$ & 6,90 & $(5)$ & NS \\
\hline \multirow{3}{*}{$\frac{\mathrm{T} 4}{\mathrm{TBG}} \cdot 10^{-3}$} & Byk Mallinckrodt & 3,94 & $(23)$ & 3,59 & $(26)$ & 3,63 & $(21)$ & 3,43 & (7) & NS \\
\hline & Becton Dickinson & 3,88 & $(19)$ & 3,32 & $(17)$ & 3,58 & $(14)$ & 3,87 & $(4)$ & NS \\
\hline & Becton D. (ARIA II) & 3,60 & $(23)$ & 3,30 & $(26)$ & 3,40 & $(21)$ & 3,38 & $(7)$ & NS \\
\hline \multirow{3}{*}{$\begin{array}{l}\text { fT4 } \\
(\mathrm{mg} / \mathrm{dl})\end{array}$} & Henning & 1,71 & $(23)$ & 1,60 & $(26)$ & 1,63 & $(21)$ & 1,66 & $(7)$ & NS \\
\hline & Byk Mallinckrodt & 1,27 & $(23)$ & 1,15 & $(26)$ & 1,10 & $(22)$ & 1,12 & $(7)$ & NS \\
\hline & Becton Dickinson & 1,18 & $(18)$ & 1,11 & $(23)$ & 1,14 & $(19)$ & 1,06 & $(7)$ & NS \\
\hline \multirow{2}{*}{$\begin{array}{l}\text { T3 } \\
\text { (ng/dl) }\end{array}$} & Becton Dickinson & 118 & $(14)$ & 131 & (13) & 131 & $(14)$ & 108 & (5) & $\cdot$ \\
\hline & Becton D. (ARIA II) & 158 & $(23)$ & 150 & $(26)$ & 141 & $(21)$ & 151 & (5) & NS \\
\hline \multirow{2}{*}{$\frac{\mathrm{T} 3}{\mathrm{TBG}} \cdot 10^{-5}$} & Becton Dickinson & 5,26 & $(14)$ & 5,74 & (13) & 5,46 & $(14)$ & 5,62 & $(5)$ & NS \\
\hline & Becton D. (ARIA II) & 8,02 &.$(23)$ & 6,80 & $(26)$ & 6,28 & $(21)$ & 7,28 & $(5)$ & NS \\
\hline \multirow{2}{*}{$\begin{array}{l}\mathrm{fT3} \\
(\mathrm{pg} / \mathrm{ml})\end{array}$} & Henning & 6,20 & $(23)$ & 6,65 & $(25)$ & 6,06 & $(20)$ & 5,74 & $(7)$ & NS \\
\hline & Becton Dickinson & 5,91 & $(23)$ & 5,96 & $(20)$ & 5,61 & $(20)$ & 5,27 & $(6)$ & NS \\
\hline $\begin{array}{l}\text { rT3 } \\
\text { (ng/dl) }\end{array}$ & $\begin{array}{r}\text { Serono } \\
. \\
\end{array}$ & 23,5 & (23) & 21,9 & (24) & $.21,2$ & (21). & 23,1 & $(6)$ & NS \\
\hline $\begin{array}{l}\text { TBG } \\
(\mathrm{mg} / \mathrm{l})\end{array}$ & Henning & 21,4 & $(23)$ & 21,5 & $(26)$ & 22,4 & $(21)$ & 18,3 & (7) & NS \\
\hline $\begin{array}{l}\text { T3-uptake } \\
(\%)\end{array}$ & Becton Dickinson & 28,8 & (23) & 28,8 & (26) & 28,2 & $(21)$ & 28,3 & (5) & NS \\
\hline
\end{tabular}


Tab. 7: Ergebnisse des Gesamteuthyreosekollektivs. Angegeben sind Mediane ( $\tilde{x})$, arithmetisches Mittel ( $\bar{x})$, der Percentilbereich $\left(P_{2,5}-P_{97.5}\right)$, die Standardabweichung $(s)$ und der Stichprobenumfang $(n)$ des gesamten Euthyreosekollektivs

\begin{tabular}{|c|c|c|c|c|c|c|}
\hline \multirow{2}{*}{$\begin{array}{l}\text { Schild- } \\
\text { drüsen- } \\
\text { Parameter }\end{array}$} & \multirow[t]{2}{*}{ Firmen } & \multicolumn{5}{|c|}{ Statistische Ergebnisse } \\
\hline & & $\tilde{\mathbf{x}}$ & $\overline{\mathbf{x}}$ & $P_{2,5}-P_{97,5}$ & $\mathbf{s}$ & $\mathbf{n}$ \\
\hline \multirow{4}{*}{$\begin{array}{l}\text { TSH } \\
(\mathrm{mU} / \mathrm{ml})\end{array}$} & Henning (IRMA) & 1,16 & 1,36 & $0,30-3,64$ & 0,87 & 175 \\
\hline & Henning (RIA) & 1,59 & 1,90 & $0,27-5,46$ & 1,27 & 177 \\
\hline & Becton Dickinson & 2,35 & 2,51 & $1,39-4,79$ & 0,79 & 173 \\
\hline & Becton D. (ARIA II) & 1,50 & 1.74 & $0,50-4,28$ & 1,04 & 177 \\
\hline \multirow{3}{*}{$\begin{array}{l}\text { T4 } \\
(\mu g / d l)\end{array}$} & Byk Mallinckrodt & 8,41 & 8,60 & $5,93-13,1$ & 1,78 & 179 \\
\hline & Becton Dickinson & 8,24 & 8,52 & $5,58-12,5$ & 1,78 & 135 \\
\hline & Bect: D. (ARIA II) & 7,78 & 8,04 & $5,38-12,1$ & 1,67 & 176 \\
\hline fT4-Index & Becton D. (ARIA II) & 7,21 & 7,41 & $5,40-10,2$ & 1,24 & 169 \\
\hline \multirow{3}{*}{$\frac{T 4}{T B G} \cdot 10^{-3}$} & Byk Mallinckrodt & 3,45 & 3,48 & $1,97-5,12$ & 0,81 & 177 \\
\hline & Becton Dickinson & 3,49 & 3,45 & $1,84-4,95$ & 0,86 & 134 \\
\hline & Becton D. (ARIA II) & 3,28 & 3,26 & $1,73-4,90$ & 0,82 & 175 \\
\hline \multirow{3}{*}{$\begin{array}{l}\text { fT4 } \\
\text { (ng/dl) }\end{array}$} & Henning & 1,64 & 1,66 & $1,29-2,11$ & 0,20 & 177 \\
\hline & Byk Mallinckrodt & 1,12 & 1,14 & $0,87-1,42$ & 0,16 & 179 \\
\hline & Becton Dickinson & 1,07 & 1,09 & $0,78-1,47$ & 0,17 & 156 \\
\hline \multirow{2}{*}{$\begin{array}{l}\text { T3 } \\
(\mathrm{ng} / \mathrm{dl})\end{array}$} & Becton Dickinson & 130 & 136 & $90,3-202$ & 31,0 & 112 \\
\hline & Becton D. (ARIA II) & 155 & 160 & $102-225$ & 31,0 & 169 \\
\hline \multirow{2}{*}{$\frac{\mathrm{T} 3}{\mathrm{TBG}} \cdot 10^{-5}$} & Becton Dickinson & 5,24 & 5,40 & $2,59-8,73$ & 1,39 & 112 \\
\hline & Becton D. (ARIA II) & 6,76 & 6,62 & $2,79-11,4$ & 2,18 & 168 \\
\hline \multirow{2}{*}{$\begin{array}{l}\text { fT3 } \\
(\mathrm{pg} / \mathrm{ml})\end{array}$} & Henning & 6,13 & 6,40 & $3,76-10,6$ & 1,84 & 174 \\
\hline & Becton Dickinson & 5,53 & 5,49 & $4,03-6,9$ & 0,73 & 166 \\
\hline $\begin{array}{l}\text { rT3 } \\
\text { (ng/dl) }\end{array}$ & Serono & 22,0 & 22,8 & $14,3-35,1$ & 5,24 & 172 \\
\hline $\begin{array}{l}\text { TBG } \\
(\mathrm{mg} / \mathrm{l})\end{array}$ & Henning & 24,2 & 26,5 & $13,6-57,3$ & 9,82 & 177 \\
\hline $\begin{array}{l}\text { T3-uptake } \\
\text { (\%) }\end{array}$ & Becton D. (ARIA II) & 28,0 & 27,7 & $21,2-32,9$ & 2,96 & 169 \\
\hline
\end{tabular}

Schrifttum:

1. aZukizana M. Pekary, A. E., hersham, J. M., PARKer, D. C.: Plasma TSH, T4 and T3 relationship in man. J. Clin. Endocrinol. Metab. 43, 533-542 (1976).

2. BALSAM, A. DOBBS. C. R., LEPPO, L. E.: Circadian variations in concentration of plasma T4 and T3 in man. J. Appl. Physiol. 39, 297-299 (1975).

3. BURR, W. A., EVANS, S. E., LEE, J., PRINCE, H. P., RAMSDEN, D. B.: The ratio of T4 to TBG in the assessment of thyroid function. Clin. Endocrinol. 11, 333-342 (1979).

4. DAVIS. P. C. J.: Ageing and endocrine function. J. Clin. Endocrinol. Metab. 8. $603-619$ (1979)

5. EVERED, C.. TUNBRIDGE. W. M. G., HALL, R.: Thyroid hormone concentrations in a large scale community survey. Effect of age, sex, illness and medication. Clin. Chim. Acta 83, 223-229 (1978).

6. FAGLIA, G., BECK-PECCOZ, P., FERRARI, C., TRAVGLINI, P.: Enhanced plasma TSH - response to TRH following oestradiol administration in man. Clin. Endocrinol. 2. $207-210$ (1973).

2. $207-210$ (1973). Clin. Lab. Invest. Suppl. 110. 62-63 (1969).
8. HARRIS, E. K., DE METS, D. L.: Estimation of normal ranges and cumulative proportions by transforming observed distributions to gaussian form. Clin. Chem. 18 , 605-610 (1972)

9. HERRMANN, J.: Altersabhängigkeit von Schilddrüsenparametern. Akt. Endokr. Stoffw. 3, 38-41 (1982)

10. HESCH, R.-D., GATZ, J., JÜPPNER, H., STUBBE, P.: TBG-dependence of agerelated variations of thyroxine and triiodothyronine. Horm. Metab. Res. 9, 141-146 (1977).

11. KNOBBER, D., ROMAHN, A., LIAPPIS, N.: Verhalten der Konzentration von TBG und T4 i.S. euthyreoter Kinder. Klinische Pädiatrie 195. 103-106 (1983).

12. KOJIMA, N SAKATA S. NAKAMURA S.: Age- and sex-related differences of serum TBG in healthy subjects. Acta Endocrinol. 104, 303-306 (1983).

serum TBG in healthy subjects. Acta Endocrinol. 104, 303-306 (1983).
13. LEMARCHAND-BERAUD. Th., RAPPOPORT, G., MARGRINI, G., REYMOND. $M$. Influence of different physiological conditions on the gonadotropins and thyrotropin responses to LHRH and TRH. Hormone and Metabolic Res. Suppl. Series No.5. 170-179 (1975).

14. LUCKE, C., HEHRMANN, R., VON MAYERSBACH, K., VON ZUR MÜHLEN. A.: 
Studies on circadian variations of plasma TSH, T4, T3 in man. Acta Endocrinol. 86, $81-88$ (1977).

15. MORLEY, J. E., SLAG, M. F. ELSON, M. K., SHAFER, R. B.: The interpretation of thyroid function tests in hospitalized patients. JAMA 249, $2377-2379$ (1983).

16. O'CONNOR, J. F., WU, G. Y., GALLAGHER, T. F., HELLMANN, L.: The 24-hour plasma thyroxine profile in normal man. J. Clin. Endocrinol. Metab. 39, 766-771 (1974)

17. PFANNENSTIEL, P., CORDES, M., PANITZ, N.: Störungen der Schilddrüsenfunktion. Münch. Med. Wschr. 129, 588-590 (1987).

18. PICKART. C. R., BAUER, M., KUBICZEK, Th., SCRIBA, P. C.: Vorteile der direkten Bestimmung des TBG in der Schilddrüsenfunktionsdiagnostik. Internist 18, 538-543 (1977).

19. ROCKER, L.: Das Verhalten von Plasmavolumen und Plasmaproteinen nach körperlichen Leistungen, körperlichem Training und Hitzeeinwirkung. Habilitationsschrift Freie Universität Berlin (1979).

20. RÖCKER, L., SCHMIDT, H. M., JUNGE, B., HOFFMEISTER, H.: Orthostasebedingte Fehler bei Laboratoriumsbefunden. Med. Lab. 28, 267-271 (1975).

21. ROOTWELT, K., SOLBERG, H. E.: Free T4, T4/TBG-ratio and other in-vitro-tests of thyroid function evaluated by discriminant analysis. Scand. J. Clin. Lab. Invest. 41 483-491 (1981).

22. SACHS, L.: Angewandte Statistik, Springer-Verlag, Berlin, Heidelberg, New York (1978).

23. SANCHEZ-FRANCO, F., GARCIA, M. D., CACICEDO, L., ESCOBAR DEL REY F.: Influence of sex phase of the menstrual cycle on TSH-response to TRH. J. Clin. Endocrinol. Metab. 5, 736-740 (1973).

24. SCHÄFER, H.: Gesundheit, Normalität und Norm. Electro Medica 46, 12-17 (1978).

25. SEIF, F. J.: Physiologische Einflüsse auf die Funktion der Schilddrüse und auf ihre Meßgrößen. Therapiewoche 30, 6329-6339 (1980).

26. SUNDERMAN, F. W.: Current concepts of "Normal Values", "Reference Values", and "Discrimination Values" in Clinical Chemistry. Clin. Chem. 21, 1873-1877 (1975).

27. WAGNER, H., HOSSDORF, T., VOSBERG, H.: Praktische Bedeutung von altersabhängigen Veränderungen der in-vitro-Meßwerte zur Schilddrüsendiagnostik. Internistische Welt 8, 285-289 (1979).

28. WEEKE, J., GUNDERSEN, H. J. G.: Circadian and 30 minutes variation in serum TSH an thyroid hormones in normal subjects. Acta Endocrinol. 89, 659-672 (1978).

\section{Anmerkung:}

Ein Teil der Blutproben wurde in den Labors der Firmen selbst analysiert und uns zur Verfügung gestellt. Hierfür danken wir besonders der Firma Henning, Berlin (TSH-IRMA, TSH-RIA fT4, fT3, TBG) sowie den Firmen Becton Dickinson (TSH, T4, fT4, T3, fT3), Byk Mallinckrodt (T4, IT4). Die restlichen Analysen wurden im eigenen Labor durchgeführt. Alle Kosten wurden von den oben genannten Firmen und der Firma Serono (rT3) übernommen.

Anschrift der Verfasser:

Gemeinschaftslabor

Dr. med. Wolfgang Eicke und

Prof. Dr. med. Lothar Röcker

Wexstraße 27

1000 Berlin 31 
Dasnemellpyoovon

Drollanges Methodenvitelfatt undeinsatzvielfaltw Und fede Mengeweiterer Plus? punktes einfache Bedies aung, thohe Prazisision und Richirigkeli, höchste Wirt schafet lich heits in Anschafs fung und täglichem Betriteb。 DiezZukunftschoneinge bauts leitchte Anfnahme neuerMethoden, fitr bichromatische Messungen vorbereites uswo

MirB Bedienerführungund grafikfähgem Druckero
Dr. Lange LP 700. Das Universal-Photometer à la carte:

\section{Ich bitte um weitere Unterlagen.}

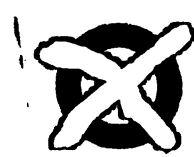

Dr.BrunolangeGmbH

Königswegi0

D=1000 Berlin 37

Telefon(030) 81602:0
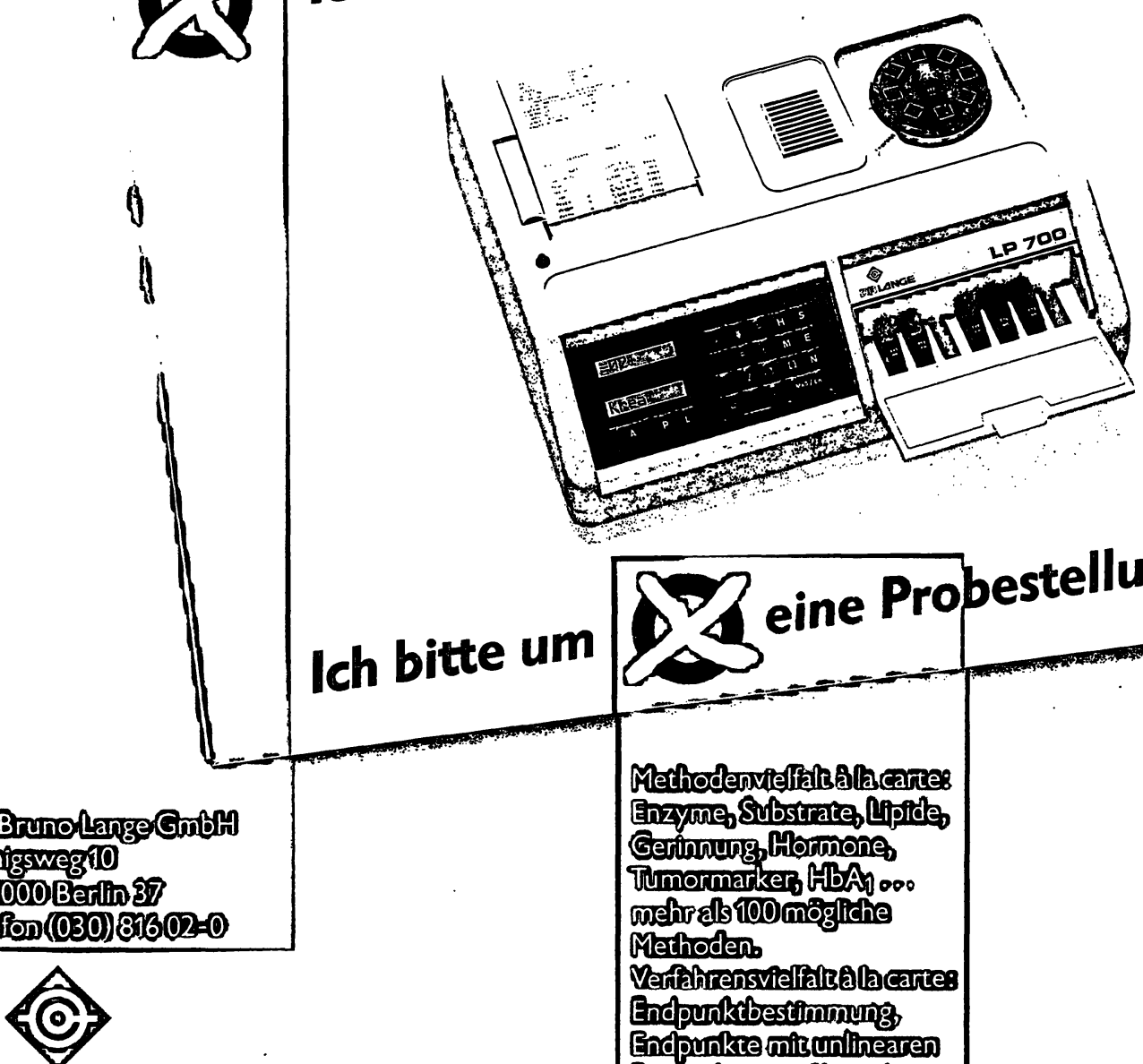

DRLANGE 


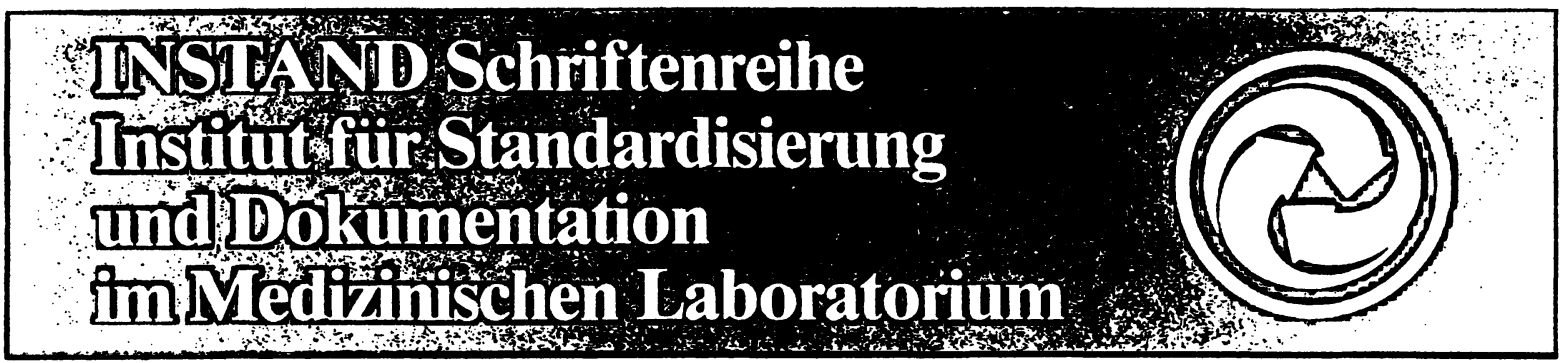

Band 7

T.O.Kleine (Hrsg.)

Liquordiagnostik

1989. ISBN 3-540-19440-1. In Vorbereitung

Band 6

W.Erb (Hrsg.)

Leitfaden der Spektralen Strahlungsmessung 1989. ISBN 3-540-19439-8. In Vorbereitung

Inhaltsverzeichnis: Einführung. - Allgemeine Begriffe, Größen, Kennzahlen. - Strahler. - Empfänger. - Spektrale Aussonderung. Spektrale Kennzahlen und Materialien. - Zusammenhang zwischen optischen Kennzahlen und Stoffkenngrößen bei photometrischen Analyseverfahren. - Anhang.

\section{Band 5}

K.-G.v. Boroviczény, R. Merten, U.P.Merten (Hrsg.) Qualitätssicherung im medizinischen Laboratorium

1987. 112 Abbildungen, 337 Tabellen. XXXII, 1071 Seiten. Gebunden DM 198,-. ISBN 3-540-13496-4

„Qualitätssicherung im medizinischen Laboratorium“ ist ein modernes, systematisches Lehrbuch und zugleich Nachschlagewerk und Ratgeber für die Gebiete Klinische Chemie, Hämatologie, Mikrobiologie und Photometerkontrollen.

Im allgemeinen Teil werden grundsätzliche Fragen, aber auch Randgebiete wie Computerisierung, Sicherheit, Kosten-Nutzen, juristische Aspekte und Normung dargestellt.

Die speziellen Teile für klinische Chemie, Hämatologie und Mikrobiologie behandeln systematisch alle Gebiete der Laboratoriumsmedizin und in der Routine vorkommenden Analysenbestandteile.

Die Kapitel sind nach einem einheitlichen Schema aufgebaut, was Übersicht und rasches Auffinden erleichtert. Sie sind von Fachleuten geschrieben, die in der Praxis stehen, von Laborchefs und Oberärzten, niedergelassenen Laborärzten und klinischen Chemikern. Im Anhang werden Begriffsdefinitionen, Formeln und ähnliches erläutert. Ausführliche Literatur- und Sachverzeichnisse bilden den Abschluß des Bandes.

\section{Springer-Verlag}

Berlin Heidelberg New York London Paris Tokyo

Heidelberger Platz 3, D-1000 Berlin 33 - 175 Fifth Ave., New York, NY 10010, USA 28, Lurke Street, Bedford MK40 3HU, England - 26, rue des Carmes, F-75005 Paris 37-3, Hongo 3-chome, Bunkyo-ku, Tokyo 113, Japan - Room 1603. Citicorp Centre, 18 Whitfield Road, Causeway Bay, Hong Kong
Band 4

R. Merten, K.-G.v. Boroviczény, R. Haeckel (Hrsg.) Methoden-, Reagenzien- und GeräteEvaluation in der Laboratoriumsmedizin

1985. 65 Abbildungen, 100 Tabellen. XVII, 489 Seiten. Gebunden DM 94,--. ISBN 3-540-13495-6

Band 3

R. Merten (Hrsg.)

Zielwert, Sollwert, Zielbereiche in der Laboratoriumsmedizin

Unter Mitarbeit von K.-G.v. Boroviczény, H.J.Jesdinsky, A.v. Klein-Wisenberg

1984. 47 Abbildungen, 57 Tabellen. XXI, 409 Seiten.

Gebunden DM 86,--. ISBN 3-540-13455-7

Band 2

\section{Größen und Einheiten in der Medizin}

A.v.Klein-Wisenberg, K.-G.v. Boroviczény, R. Merten (Hrsg.) Neuauflage in Vorbereitung

Band 1

K. Osburg (Hrsg.)

\section{Personalbedarf und Kosten im medizinischen Laboratorium}

Anleitung zur Ermittlung

Unter Mitarbeit von P.M. Bayer, K. G.v. Boroviczény, G. Fischer, M. Fischer, R. Haeckel, O. Henker, A. Prüsse, G. Schumann, M.Walker

3., überarbeitete und erweiterte Auflage. 1987. 58 Abbildungen, 17 Tabellen. XVIII, 362 Seiten. Gebunden DM 145,--

ISBN 3-540-18451-1

Die 3., verbesserte und erweiterte Neuauflage des erstmals 1976 als Band 1 der INSTAND-Schriftenreihe erschienenen Buches enthält zusätzlich ein Kapitel zur Kostenermittlung und - aus aktuellem Anlaß - ein neues Kapitel über deskriptive Laborstatistik. Das Buch faßt somit alle bekannten Verfahren zur Personalbedarfsberechnung und zur Kostenermittlung im Medizinischen Laboratorium zusammen und ist als Anleitung zur selbständigen Durchfuihrung dieser Berechnungen gedacht.

Preisänderungen vorbehalten 